\title{
Contribuciones de la genética y la proteómica al estudio de la enfermedad de Chagas
}

\author{
Teresa López-Ordóñez, PhD, (I) Francisco Panzera, PhD, ${ }^{(2,3)}$ Ezequiel Tun-Ku, Biól,(I) \\ Inés Ferrandis, MSc, ${ }^{(3)}$ Janine M Ramsey, PhD. (1)
}

\section{López-Ordóñez T, Panzera F,Tun-Ku E, Ferrandis I, Ramsey JM. \\ Contribuciones de la genética y la proteómica \\ al estudio de la enfermedad de Chagas. Salud Publica Mex 2009;5 I supl 3:S4I 0-S423.}

\section{Resumen}

La enfermedad de Chagas representa uno de los problemas más importantes de salud pública en el continente americano. El conocimiento sobre el genoma y el proteoma de los agentes de esta infección es esencial para desarrollar herramientas precisas y eficaces a corto y largo plazo y prevenir la transmisión. En el presente documento se destacan los aportes que han permitido mejorar el diseño, la implementación y la eficacia de las actividades de vigilancia y control de la enfermedad. Se revisan la contribución de la información genómica o proteómica sobre la distribución geográfica de los vectores, y la diversidad y la dinámica poblacional, además de la identificación de poblaciones y especies blanco para control. Por otra parte, se analiza la forma en que el conocimiento del genoma del parásito ha contribuido al diagnóstico de la infección, el estudio de las poblaciones de Trypanosoma cruzi, el tratamiento farmacológico y la interacción del parásito con sus hospederos. Una revisión de estas contribuciones incluye los temas de investigación básica y aplicada más destacados para el futuro inmediato.

Palabras claves: enfermedad de Chagas; Triatominae; Trypanosoma cruzi
López-Ordóñez T, Panzera F,Tun-Ku E, Ferrandis I, Ramsey JM.

Genomic and proteomic contributions

for Chagas disease control.

Salud Publica Mex 2009;5 I suppl 3:S4I 0-S423.

\section{Abstract}

Chagas disease represents one of the more significant public health problems in the Americas. Information regarding the genome and proteome of vectors and parasite, as well as their interactions, will be essential to develop specific and effective diagnostic and preventive tools.Advances that have contributed to the design, implementation, and efficacy of disease surveillance and control activities are reviewed. Genomic and proteomic information has contributed to a better understanding of vector distributions and dispersion, diversity, population dynamics, and control targets (populations and species). In addition, genomic and proteomic studies have impacted parasite diagnostics, Trypanosoma cruzi population dynamics, pharmacological treatment and knowledge of parasite-host interactions. Discussion of these contributions includes expectations for future basic and applied research questions.

Key words: Chagas disease; Triatominae; Trypanosoma cruzi

(I) Centro Regional de Investigación en Salud Pública, Instituto Nacional de Salud Pública. Tapachula, Chiapas, México.

(2) Centro de Investigación sobre Enfermedades Infecciosas, Instituto Nacional de Salud Pública. Cuernavaca, Morelos, México.

(3) Sección Genética Evolutiva, Facultad de Ciencias, Universidad de la República. Montevideo, Uruguay.

Fecha de recibido: 28 de julio de 2008 - Fecha de aceptado: 25 de marzo de 2009 Solicitud de sobretiros: Dra. Janine Ramsey. Centro Regional de Investigación en Salud Pública, Instituto Nacional de Salud Pública. $4^{\mathrm{a}}$. Norte esq. 19a. Poniente s/n. col. Centro. 30700, Tapachula, Chiapas, México. Correo electrónico: jramsey@insp.mx 
L a enfermedad de Chagas, causada por la infección del parásito Trypanosoma cruzi y transmitida, sobre todo al hombre, por insectos hemípteros pertenecientes a la subfamilia Triatominae, representa uno de los problemas más importantes de salud pública en el continente americano. Hacia finales de la década de 1980, se calculaba que de 16 a 18 millones de personas estaban infectadas con el parásito y que 90 a 100 millones vivían en situación de riesgo, con una incidencia de 450000 nuevas infecciones por año. ${ }^{1}$ En términos de impacto socioeconómico, la enfermedad de Chagas representa la parasitosis más importante en América. ${ }^{2}$ A pesar de los programas exitosos de control vectorial en Sudamérica, aún persisten entre 10 y 12 millones de personas infectadas y 200000 nuevos casos por año. ${ }^{3-5}$ Tan sólo en México se calcula que existen 2 millones de personas infectadas, 650000 casos crónicos atendidos actualmente por los servicios de salud, 69000 nuevos casos anuales y una mortalidad no menor de 25000 por año. ${ }^{6}$

Si se adopta una posición optimista sobre la decisión política y económica de desarrollar programas precisos y sustentables para el control vectorial de la transmisión de Trypanosoma cruzi en todas las regiones del continente americano a corto o mediano plazos, se requerirán todavía herramientas más eficaces para prevenir la presencia del vector en el hábitat doméstico, medir la transmisión del parásito al ser humano, el diagnóstico preciso y oportuno de la infección, el tratamiento terapéutico, la prognosis de desarrollo del cuadro crónico, así como de tratamientos de largo alcance. Los conocimientos sobre la genética/genoma y los proteomas del vector y el parásito serán esenciales para desarrollar instrumentos precisos y eficaces para complementar las soluciones socioculturales e impedir la transmisión. Una alta proporción del genoma de $T$. cruzi ya se ha publicado ${ }^{7}$ y está en proceso la secuenciación del genoma de Rhodnius prolixus. Ya existe un consorcio de instituciones que trabajan en colaboración sobre el genoma de Triatoma dimidiata, única especie que se distribuye naturalmente entre América del Norte y América del Sur. En el presente trabajo se exponen las principales aportaciones de la genética al control de los insectos vectores, así como las futuras contribuciones que puedan realizarse para reducir en grado significativo la transmisión vectorial. Se revisan aquí los avances en el conocimiento de la estructura poblacional de $T$. cruzi, las necesidades de información para desarrollar diversas herramientas para el diagnóstico y la prevención de la transmisión, además de las evidencias moleculares que permitirán desarrollar estrategias eficaces para el control farmacológico y alternativo de la infección.

\section{Triatominae}

Existen diferentes formas de transmisión del parásito, pero la principal es la vectorial (>96\% en México). En ausencia de una vacuna y tratamientos médicos farmacológicos más eficaces, la herramienta más importante para combatir la transmisión de esta enfermedad es el control doméstico de los insectos vectores mediante el rociado de las casas con insecticidas residuales, la mejoría de las viviendas y la activación de programas de participación comunitaria para la prevención y la vigilancia. El tamizaje serológico de la sangre destinada a transfusión es esencial para complementar el control vectorial.

A partir de 1991 se instituyó una serie de programas o iniciativas intergubernamentales y regionales enfocados en la eliminación de la transmisión vectorial (mediante la eliminación de los triatominos domésticos) y la transfusional (mediante un control completo de tamizaje en los bancos de sangre). El mayor éxito con control químico lo alcanzó la Iniciativa del Cono Sur (INCOSUR), ${ }^{8}$ que se tradujo en una disminución de la distribución geográfica del principal vector doméstico, Triatoma infestans. Las dificultades encontradas por los programas multinacionales indican la necesidad de aplicar nuevas medidas asociadas con los aspectos socioculturales de la transmisión y vigilancia, y con la ecología y genética del vector. ${ }^{9}$

Un factor crucial para la reducción de la transmisión vectorial es el conocimiento de las características biológicas de los insectos, incluidas las ecológicas y genéticas. ${ }^{10}$ La capacidad de dispersión de una especie (tanto de forma natural como por la intervención del hombre), su adaptación a ocupar diversos hábitats silvestres y su capacidad de invadir y colonizar ambientes perturbados (especialización ecológica), así como los mecanismos del intercambio de individuos entre ecotopos silvestres, perturbados y domésticos, son factores esenciales que determinan qué tipo de programas deben instituirse para reducir la transmisión vectorial de la enfermedad de Chagas al hombre a corto y largo plazos.

Cualquier programa de control necesita reconocer cuáles son las especies blanco sujetas a intervención, para lo cual es indispensable una correcta identificación taxonómica. La mayoría de los triatominos se reconoce mediante caracteres morfológicos externos de la etapa adulta, ${ }^{11}$ pero existen algunos grupos de especies difíciles de diferenciar aun en esa etapa o en la fase ninfal; entre ellos cabe destacar por su importancia vectorial a los complejos dimidiata, phyllosoma, brasiliensis, sordida y prolixus. La similitud morfológica entre especies hermanas se debe a una divergencia reciente, o bien a una convergencia 
morfológica. ${ }^{12}$ Estudios fenéticos y genéticos sugieren que la especiación en Triatominae es un proceso muy rápido y lo determinan sobre todo factores ecológicos y la deriva genética. Esto es en particular importante para el control vectorial, ya que se ha observado que la adaptación a ambientes domésticos puede estar acompañada de rápidos cambios morfológicos, incluso antes del establecimiento de barreras reproductivas o genéticas. ${ }^{13}$ Desde 1997, la aplicación de diversas metodologías genéticas ha permitido identificar especies crípticas o gemelas, es decir, especies morfológicamente indistinguibles pero que están aisladas en términos reproductivos y tienen importancia epidemiológica distinta. Entre estos estudios deben destacarse aquéllos que incluyen especies con importancia vectorial significativa, tales como los del grupo sordida, ${ }^{14,15}$ grupo brasiliensis, ${ }^{16}$ grupo dimidiatat ${ }^{17,18}$ y los ya mencionados en la diferenciación entre $R$. prolixus y $R$. robustus. Aún falta dilucidar la diferenciación dentro de las especies del grupo phyllosoma, integrado por múltiples especies endémicas de México que representan $67 \%$ de la transmisión vectorial en este país. ${ }^{6}$

De norte a sur, son múltiples los complejos de especies de Triatominae y la mayor parte juega un papel relevante en la transmisión de la enfermedad de Chagas. En Norteamérica (México y Estados Unidos de América) se destacan los complejos rubida, protracta, phyllosoma y dimidiata; en Centroamérica sólo se encuentran de forma autóctona dos subespecies del complejo dimidiata y dos especies del complejo protracta. A partir de Panamá se destaca Rhodnius pallescens y en los países andinos y la Amazonia, múltiples especies de R. prolixus y robustus, dos subespecies del complejo dimidiata, el complejo brasiliensis en Brasil y el grupo sordida que se extiende hasta Argentina. ${ }^{19}$

A pesar de los avances recientes en estudios sobre la genética, incluida la poblacional de los triatominos, $, 20,21$ pocas especies o complejos se han estudiado a profundidad como T. infestans, R. prolixus o el complejo dimidiata. En seguida se resumen los estudios sobre estas especies, los cuales han servido para extender el conocimiento sobre la subfamilia y diseñar mejores barreras contra su domesticación.

\section{Triatoma infestans}

Triatoma infestans representa el mejor ejemplo de dispersión y adaptación exitosa al ambiente doméstico observado en la subfamilia Triatominae. En 1991 se consideraba el principal vector y el más extendido en América del Sur (no se ha registrado en Norteamérica o Centroamérica). Era causante de más de la mitad de los 18 millones de personas infectadas con T. cruzi en el continente. ${ }^{1}$ Su distribución abarcaba más de 6 millones de kilómetros cuadrados, incluida las extensas regiones de Argentina, Bolivia, Brasil, Chile, Paraguay, Uruguay y sur de Perú. Durante los 10 primeros años de la Iniciativa del Cono Sur (INCOSUR) se fumigaron con insecticidas más de 2.5 millones de casas y como resultado se redujo en grado sustancial la distribución de T. infestans a menos de 1 millón de kilómetros cuadrados que ocupa hoy día (David Gorla, comunicación personal). Un elemento clave para el éxito de la INCOSUR fue el conocimiento de las características biológicas del vector.

Triatoma infestans se encuentra casi exclusivamente en ambientes domésticos y peridomésticos. Su presencia en entornos silvestres sólo se ha confirmado en valles andinos de Cochabamba y Sucre en Bolivia. ${ }^{22-24}$ Este hallazgo junto con reconstrucciones históricas basadas en las migraciones humanas sugiere que Bolivia era el centro de origen y domesticación de T. infestans, a partir del cual las poblaciones domésticas se dispersaron al resto de América del Sur. ${ }^{25}$ Resultados genéticos basados en isoenzimas ${ }^{26}$ y en variaciones cromosómicas y del tamaño genómico ${ }^{27}$ confirmaron a Bolivia como centro de origen. Sin embargo, lo más sorprendente es que los insectos que se dispersaron desde Bolivia hacia regiones no andinas sufrieron una drástica disminución del tamaño de sus genomas. Las poblaciones derivadas de Argentina, Brasil, Paraguay y Uruguay presentan una reducción de 30 a $40 \%$ del DNA genómico en comparación con las ancestrales de Bolivia. Esta notoria reducción del contenido de DNA supone cambios adaptativos de tal forma que los insectos de menor genoma experimentaron una rápida y exitosa dispersión y adaptación a los domicilios, pero como contraparte se atenuó en gran medida su capacidad de retornar a ambientes silvestres. ${ }^{27}$ Sólo de manera excepcional se han detectado poblaciones de T. infestans silvestres en regiones no andinas. ${ }^{28,29}$ Por lo anterior, T. infestans en la mayor parte de su rango de distribución es una especie introducida en fecha reciente, muy adaptada al ambiente doméstico y con capacidad reducida para retornar al medio silvestre y, por consiguiente, susceptible a las campañas de control químico. Estas características explicarían el éxito de su erradicación en la mayor parte de los países del Cono Sur y justificarían continuar el control químico para la eliminación del vector. ${ }^{30}$

En Bolivia existen focos silvestres que al parecer son la fuente de origen de las reinfestaciones encontradas después de control. Estudios basados en morfometría, ${ }^{31}$ y en fecha más reciente en microsatélites (Noireau, comunicación personal), apoyan la hipótesis de un aislamiento entre los ecotopos silvestres y domésticos de T. infestans en Cochabamba. Estos estudios revelan, al menos en esa región, la importancia epidemiológica que se ha atribuido a los focos silvestres como fuente 
primaria de las reinfestaciones. La detección de nuevos focos silvestres en Bolivia, y su posible ocurrencia en regiones vecinas de Paraguay y Argentina, plantea la necesidad de determinar su capacidad de reinvadir ambientes domésticos. ${ }^{32} \mathrm{El}$ desarrollo de nuevos marcadores moleculares, como los microsatélites, permitirá calcular de forma mas precisa la magnitud del flujo de individuos entre focos silvestres y domésticos ${ }^{33,34} \mathrm{y}$, por lo tanto, su importancia vectorial.

La reciente detección de poblaciones de $T$. infestans resistentes a insecticidas de tipo piretroides en el norte de Argentina, ${ }^{35}$ extendidas hacia el centro y sur de Bolivia, es el reto más importante y novedoso que enfrenta el control de esta especie. Es prioritario eliminar estas poblaciones, así como es indispensable determinar cuál es el componente genético de esta resistencia, incluidas su expresión y herencia. La identificación de marcadores fenéticos o genéticos que discriminen a los individuos susceptibles de los resistentes permitirá conocer la dispersión de la resistencia y por tanto ayudará en grado considerable al diseño de las campañas de control vectorial. Éste es uno de los objetivos de un proyecto en curso desde el año 2005, integrado por un numeroso grupo de investigadores de Argentina, Bolivia, Francia, Paraguay y Uruguay, bajo el financiamiento de la Comunidad Europea (proyecto ATU-SSA 2004-515942) y cuyos resultados han demostrado poca dispersión de la resistencia a los piretroides, sólo con resistencia a la deltametrina. Sin embargo, se ha observado que algunas cepas o poblaciones de T. infestans resistentes a deltametrina son susceptibles a los organofosforados. ${ }^{35-37}$

\section{Rhodnius prolixus}

Rhodnius prolixus es una especie distribuida en Venezuela, Colombia y varios países de Centroamérica; en la mayor parte de estas naciones es la principal especie vectora de T. cruzi. Al igual que T. infestans, R. prolixus en Centroamérica es una especie exclusivamente doméstica, introducida de forma accidental por el hombre. ${ }^{38}$ Análisis mediante morfometría, RAPD e isoenzimas ${ }^{39}$ indican que las poblaciones centroamericanas, hasta ahora incapaces de colonizar ambientes silvestres, presentan una menor variabilidad genética que las de Sudamérica, lo que las convierte en poblaciones muy susceptibles a las campañas de control químico. Los auspiciosos logros de los programas de control vectorial alcanzados por la Iniciativa de América Central ${ }^{40}$ corroboran los estudios genéticos. Otro aporte importante de la genética al control de R. prolixus fue la diferenciación entre R. prolixus y R. robustus, especies morfológicamente muy similares. Hasta hace pocos años se pensaba que la presencia de $R$. robustus en palmeras era la fuente de origen de R. prolixus doméstico. Estudios mediante morfometría geométrica ${ }^{41}, \mathrm{RAPD}^{42}$, y sobre todo el análisis de fragmentos mitocondriales, ${ }^{43}$ confirmaron que se trata de especies distintas y, como consecuencia, blancos separados y diferenciados para las campañas de control vectorial.

Bajo el financiamiento de los Institutos Nacionales de Salud de los Estados Unidos (NIH) actualmente se encuentra en proceso la secuenciación del genoma completo de $R$. prolixus, primera especie de triatominas estudiada por esta metodología por la Universidad de Washington (The Genome Sequencing Center). La secuenciación del genoma, con un tamaño estimado de 670 $\mathrm{Mb}^{44}$ aportará una información inestimable acerca de distintos aspectos del insecto. No sólo proveerá información básica para estudios proteómicos y filogénicos, sino que facilitará en particular la identificación de productos génicos que intervienen en la interacción hospedero-parásito o la identificación de genes activos en el desarrollo del insecto; esto hará posible interferir la transmisión del parásito.

\section{Complejo dimidiata}

El complejo dimidiata se distribuye desde México, Centroamérica completa, Colombia, Ecuador y Perú; en varios de estos países es el principal vector de la enfermedad de Chagas. A lo largo de su rango de distribución se encuentra en ambientes domésticos y silvestres y ocupa ecotopos muy diversos. Estas especies presentan variaciones morfológicas y cromáticas que han generado una extensa discusión acerca de su estatus taxonómico. ${ }^{11}$ Los serios problemas taxonómicos sumados a la gran dispersión geográfica y diversidad de ecotopos que ocupa esta especie ${ }^{45-47}$ dificultan las medidas de control vectorial.

La primera evidencia de que esta especie estaba constituida por más de un grupo taxonómico la aportó el análisis de secuencias del ITS-2 del DNA ribosomal. ${ }^{17}$ Se determinó una clara diferenciación genética entre $T$. dimidiata de la península de Yucatán y el resto de las poblaciones distribuidas desde México hasta Colombia. Los resultados revelaron que existe un clino norte-sur de poblaciones poco diferenciadas morfológicamente, las cuales se encuentran en ambientes silvestres y domésticos. Las poblaciones de Ecuador y del norte de Perú son exclusivamente domésticas sin ecotopos silvestres conocidos $^{48}$ y presentan una gran similitud genética con las poblaciones de Guatemala y Honduras, en lugar de representar derivados naturales del supuesto clino norte-sur. ${ }^{17}$ Estudios con marcadores mitocondriales (LSU y ND4) sugirieron por lo menos tres clados o especies según una divergencia combinada superior a 
$6.8 \%,{ }^{49}$ datos que se correlacionan con hidrocarburos cuticulares $^{50}$ y morfometría. ${ }^{51}$ Recientes estudios que incluyen el análisis de elementos cromosómicos, genes ribosomales y del tamaño genómico han sugerido la existencia de tres especies crípticas genéticamente diferenciadas pero morfológicamente muy similares en $T$. dimidiata. 18,52 Cada una de las especies presenta una distribución geográfica particular, un potencial de colonización del ambiente doméstico variable y, potencialmente, una importancia epidemiológica distinta. Por lo anterior, T. dimidiata estaría integrada por un complejo de especies, con hábitats y capacidades de domiciliación distintos, lo que las convierte en blancos diferenciados para las campañas de control vectorial. ${ }^{53,54}$

Dada la gran diversidad de ecotopos, es indispensable el análisis genético de las especies del complejo dimidiata, a fin de esclarecer su susceptibilidad al control químico y el origen de las reinfestaciones en viviendas humanas tras intervenciones químicas y comunitarias. Con el objetivo de planificar y mejorar las medidas de control vectorial y comunitario, resulta indispensable la diferenciación y reconocimiento de cada especie y población críptica, luego de establecer no sólo sus características genéticas, sino en especial sus capacidades diferenciales de invadir y al final colonizar el ambiente doméstico.

Esta información será también importante para analizar las variables de domesticación de las especies del complejo phyllosoma, tal vez descendientes del complejo dimidiata, que se dispersaron al poniente y sur por el eje volcánico en México (entre la Sierra Madre Oriental y la Occidental y al norte y sur de la costa pacífica).

La aplicación de distintos marcadores genéticos en las principales especies del grupo phyllosoma muestra una llamativa falta de diferenciación, nunca antes observada en otros complejos de especies. Mediante isoenzimas no se encontraron locus polimórficos, ${ }^{55,56}$ ni tampoco con el análisis de RAPD. ${ }^{57}$ En este último trabajo, los 16 a 22 cebadores utilizados discriminan $T$. pallidipennis de T. longipennis y T. picturata, mientras que hay una superposición entre las dos últimas. Estudios comparativos de secuencias del segundo espaciador interno (ITS-2) del ADN ribosomal muestran una variación baja . Las diferencias nucleotídicas identificadas se encuentran entre dos y cuatro nucleótidos, aunque no se observaron variaciones entre T. longipennis, T. picturata, ${ }^{17}$ T. bassolsae, T. pallidipennis y entre T. mazzottii y T. phyllosoma.$^{58}$ Todos estos datos indican sin duda una reciente divergencia de las especies del complejo phyllosoma desde un ancestro común. En fecha reciente, resultados filogenéticos mediante genes mitocondriales sugieren que T. recurva pertenecería al complejo phyllosoma, emparentado de manera estrecha con T. longipennis. ${ }^{59}$ Otra especie, morfológicamente relacionada con $T$. recurva y no asignada a ningún complejo, es T. gerstaeckeri, una de las 10 especies vectoras más importantes de México.

\section{Perspectivas para el control vectorial}

Dada la diversidad de especies de triatominos que intervienen en la transmisión vectorial, ${ }^{60}$ las medidas de control deben ajustarse a cada situación particular, para lo cual resulta imprescindible conocer las características fisiológicas, ecológicas y genéticas de los insectos vectores. Como se ha mencionado ya para T. infestans y $R$. prolixus, los estudios genéticos han permitido el reconocimiento de poblaciones muy adaptadas al ambiente doméstico con menor variabilidad genética, lo cual las convierte en blancos muy vulnerables y atractivos para el control químico. El estudio de otras especies parece sugerir que este fenómeno de reducción de la variabilidad genética parece estar más extendido de lo que originalmente se pensaba. Tal sería el caso de las poblaciones domésticas de R. ecuadoriensis en el norte del Perú ${ }^{61}$ y Panstrongylus megistus en el noreste de Brasil. ${ }^{62}$

La mayoría de las especies de triatominos es difícil de controlar, ya que además de presentar poblaciones domésticas, conservan ecotopos silvestres, como diversas especies integrantes de los complejos dimidiata, phyllosoma, sordida, y brasiliensis. En estas especies se describen con frecuencia reinfestaciones de las casas a los pocos meses del rociado con insecticidas. ${ }^{40,63,64}$ Es fundamental determinar cuál es el origen de las reinfestaciones, para lo cual caben tres posibilidades: se producen por ejemplares que sobrevivieron al rociado (rociado mal aplicado), individuos resistentes a las intervenciones o bien la reinfestación se produce porque hay nuevas invasiones de insectos desde otros focos silvestres y domésticos cercanos que no se trataron. Para poder diseñar con éxito las medidas de control y vigilancia, es indispensable discernir el origen de los individuos reinfestantes y para ello es muy valiosa la aplicación de distintos marcadores genéticos. ${ }^{20,21} \mathrm{Algu}$ nos estudios indican que si bien existe un flujo genético entre hábitat silvestre y doméstico, éste es relativamente bajo y no es un obstáculo importante para el control de las poblaciones domésticas a corto plazo, aunque es necesario desarrollar estrategias complementarias para el control de largo plazo. ${ }^{65}$ En otros casos, el control de las poblaciones peridomésticas son de primordial importancia para la reducción de los focos domésticos. ${ }^{66,67}$

Un reto muy importante para la genética en relación con el control es el estudio de la resistencia a insecticidas que se ha detectado recientemente en poblaciones de T. infestans del norte Argentino y Bolivia. ${ }^{35}$ La resistencia a piretroides, fenómeno muy extendido 
en otros insectos vectores como los mosquitos, es excepcional en los triatominos. Para alcanzar el objetivo del INCOSUR de eliminar la transmisión vectorial por T. infestans es indispensable precisar cuáles son los mecanismos bioquímicos y genéticos que generan la resistencia, de tal manera que se evite su dispersión hacia otras regiones.

\section{Trypanosoma cruzi}

Los avances recientes en genómica de las infecciones parasitarias han proporcionado, como uno de los resultados más espectaculares, la secuenciación de los tres patógenos de la familia Trypanosomatidae, como un proyecto único. ${ }^{7}$ Se espera que el conocimiento de la secuencia completa del genoma de Trypanosoma cruzi conduzca a la comprensión del parasitismo y la virulencia y al desarrollo de los campos de diagnóstico y tratamiento de la enfermedad de Chagas.

\section{Diagnóstico}

Una de las principales aplicaciones de la genética al estudio de $T$. cruzi fue resultado de la necesidad de mejorar el diagnóstico de la infección en los vectores y los hospederos mamíferos. En particular, esto se debió a que cualquier programa de control de la enfermedad de Chagas tiene que diseñarse a partir de las condiciones particulares de prevalencia y distribución de la infección. Para detectar la infección por T. cruzi, ha sido necesario emplear sobre todo dos herramientas diagnósticas: los métodos serológicos y los métodos parasitológicos. $\mathrm{Al}$ considerar la evolución de la infección en los hospederos humanos, la permanencia de los parásitos en la circulación sanguínea por muy corto tiempo después de su entrada, su localización en tejidos de difícil acceso y la escasa cantidad de ellos en relación con el volumen de sangre con el tiempo y según la etapa de la enfermedad, es claro que el diagnóstico tradicional parasitológico (y todavía de primera línea en algunos países) por microscopia carece de sensibilidad. ${ }^{68}$ El uso de la reacción en cadena de la polimerasa (PCR) para detectar la presencia del parásito es la herramienta más usada como método molecular de diagnóstico, con la ventaja adicional de que aun cuando se encuentre en diminutas cantidades, el $\mathrm{ADN}$ del parásito se puede amplificar. Estos ensayos han utilizado gran variedad de iniciadores para amplificar diversos genes: desde el ADN del cinetoplasto ${ }^{69}$ hasta fragmentos de genes nucleares, incluidas secuencias nucleares repetitivas, ${ }^{70,71}$ una secuencia que codifica a una proteína flagelar ${ }^{72}$ y combinaciones de secuencias en PCR multiplex. ${ }^{73,74}$ Esta metodología ha sido efectiva en la detección de casos agudos y crónicos de la enfermedad y ha mostrado consistencia con las pruebas serológicas $^{75-78}$ y la detección de infección de vectores. ${ }^{77,79,10}$ Se ha realizado incluso la medición de las fluctuaciones en la parasitemia durante la infección crónica mediante PCR cuantitativa. ${ }^{80}$ Con la publicación de la secuenciación del genoma de T. cruzi, puede preverse que los métodos de diagnóstico moleculares adquieran mayor oportunidad de desarrollo, siempre que se identifiquen genes del parásito particulares para el diagnóstico o el seguimiento del tratamiento.

Las dificultades para establecer procedimientos estándares y asegurar la sensibilidad del diagnóstico parasitológico con PCR han propiciado el uso universal del diagnóstico serológico para detectar la infección humana. Los ensayos actuales principales son la inmunofluorescencia indirecta (IFI), los ensayos enzimáticos inmunoadsorbentes (ELISA) y el Western blot, los cuales se basan en la detección de anticuerpos generados por la presencia del parásito. ${ }^{1}$ Varios métodos bioquímicos y moleculares se han utilizado para purificar y caracterizar los antígenos inmunodominantes principales, con el objetivo de mejorar la sensibilidad y la especificidad de las pruebas diagnósticas serológicas. ${ }^{81-83}$ Sin embargo, no existe un consenso universal para ellas y se ha debatido también el hecho de que la diversidad genética de las cepas por área geográfica y los linajes del parásito pueden ser factores que determina la sensibilidad. ${ }^{84}$ Las técnicas moleculares han permitido contar con proteínas recombinantes del parásito para utilizarlas en las pruebas serológicas y evitar los procesos de cultivo, extracción y purificación de antígenos. De este modo se ha disminuido el tiempo invertido en los ensayos y la variación en la composición del antígeno de un lote a otro. Los resultados de los ensayos con proteínas recombinantes no difieren estadísticamente respecto de los realizados con extractos de parásitos, al menos no en seis países de Latinoamérica. ${ }^{85-89}$

Los ensayos para diagnóstico de la nueva generación parecen ser los microarreglos; estas plataformas tienen el potencial de realizar diagnósticos de enfermedades infecciosas diferenciales altamente específicos, por lo que el número de aplicaciones excede en mucho el disponible por cualquier otra metodología conocida. ${ }^{90,91}$ En el caso de las enfermedades infecciosas, esta plataforma ha permitido por ejemplo el estudio poblacional y patrones de resistencia de la tuberculosis. ${ }^{92}$ Se ha propuesto incluso detectar, mediante una sola prueba, cualquier microorganismo perteneciente a un grupo recién nombrado (Panmicrobial database) que incluye 29495 especies diferentes. ${ }^{93}$ Esto es posible debido a que en un espacio de $70 \mathrm{~mm}$ X $20 \mathrm{~mm}$ es posible acomodar 244000 oligonucleótidos que funcionan como sondas para la detección de los microorganismos (de los cuales provienen las sondas), en muestras de sangre, exudados 
faríngeos, orina y otros tejidos. A partir de estos tejidos se extrae el ARN y éste se incuba con los portaobjetos que llevan las sondas; las hibridaciones se detectan por fluorescencia. ${ }^{93}$

Si se considera la necesidad de mejorar el diagnóstico de la enfermedad de Chagas y la disponibilidad de secuencias identificadas como genes verdaderos de la superficie del parásito, esta metodología podría posibilitar lo siguiente:

1. Detectar infecciones agudas con una sola prueba común, sobre todo en los casos pediátricos, los cuales presentan por lo general baja respuesta de anticuerpos.

2. Realizar el seguimiento de los pacientes tratados para evaluar la eliminación del parásito y la evolución de su respuesta inmunitaria posterior al tratamiento.

3. Efectuar una evaluación rápida de los casos sospechosos por datos clínicos en las unidades de atención primaria con la finalidad de iniciar el tratamiento de manera inmediata de los casos agudos (antes de seis meses). En la actualidad, el resultado de una prueba de Chagas puede tardar entre 6 y 12 meses en llegar a la clínica de origen de la muestra.

4. Realizar la detección rápida de transmisión congénita, ya que será posible diferenciar la respuesta inmunitaria de la madre del niño. Hoy en día se requiere un periodo de nueve meses de espera antes de contar con un diagnóstico serológico válido, para descartar la detección de anticuerpos maternos en el infante. En estos casos, la detección molecular del parásito puede ser de utilidad, si bien necesita la preservación de la sangre, el transporte a un laboratorio especializado y la utilización de técnicas complejas y reactivos de difícil conservación.

5. Practicar el tamizaje rápido de los migrantes (provenientes de zonas endémicas hacia países sin transmisión vectorial).

6. Instituir un sistema mejorado de tamizaje de bancos de sangre. Los falsos positivos frecuentes con los métodos de diagnóstico comerciales en uso actual disminuyen la cantidad efectiva de unidades disponibles para la transfusión, situación delicada en los países en los que la cultura de donación de sangre no es ampliamente compartida.

7. Desarrollar una prueba serológica sencilla que requiere equipo mínimo, en un formato a prueba de humedad y temperatura elevadas, condiciones frecuentes en las zonas endémicas.

\section{Tratamiento farmacológico}

Los dos medicamentos que se utilizan en la actualidad para el control parasitario de la enfermedad de Chagas han estado en uso por más de 40 años: nifurtimox y benznidazol. Ninguno de ellos es efectivo en la totalidad de los casos en los que se han aplicado y para ambos se han notificado efectos adversos graves. ${ }^{94}$ El Grupo Científico de Trabajo de la OPS ha reconocido que los fármacos disponibles para el control de la infección no son los ideales y que se desconoce si éstos pueden detener el progreso de la enfermedad. ${ }^{95}$ Esta percepción de ausencia de medicamentos eficaces para el control de la infección ha promovido el desarrollo de nuevas formulaciones, tras tomar como blancos a las moléculas que participan en las vías metabólicas del parásito que difieren de las existentes en los mamíferos. Dentro de estos estudios, destaca el uso de los inhibidores de las proteasas de cisteína con efectos directos sobre la cruzipaína, esencial para el crecimiento del parásito. ${ }^{96,97} \mathrm{Se}$ han reportado los inhibidores de la biosíntesis de esteroles, indispensables para la formación de membranas del parásito, como agentes con excelentes propiedades farmacocinéticas: concentraciones mínimas inhibitorias, alto volumen de distribución, vida media larga y una extensa distribución en tejidos; asimismo, su farmacodinamia es excelente y tiene pocos (en algunos casos nulos) efectos adversos. ${ }^{98-100}$ Los flavonoides aislados de plantas, de los cuales se desconoce el mecanismo de acción, son compuestos relacionados estructuralmente que han probado su eficacia in vitro e in vivo contra T. cruzi. ${ }^{101}$ Los inhibidores de algunos metabolitos intermediarios del metabolismo de los aminoácidos, en especial la enzima cinasa de arginina, ${ }^{102}$ los inhibidores de la reductasa de dihidrofolato, ${ }^{103}$ los inhibidores de la transialidasa, un factor de virulencia que induce la apoptosis de las células inmunitarias, ${ }^{104}$ son otros ejemplos de moléculas propuestas como blancos para el diseño de medicamentos para controlar la infección. Aunque hasta la fecha las moléculas propuestas como medicamentos no han sido productos de los análisis genéticos funcionales, la tecnología derivada de la proteómica permitirá el tamizaje de estas moléculas con actividad tripanocida a fin de detectar cambios en los patrones de expresión de proteínas en respuesta a la exposición de fármacos como en el caso documentado de Plasmodium. ${ }^{105}$

El avance del conocimiento en la fisiología y metabolismo de T. cruzi derivado de la atribución de funciones a los genes secuenciados en el proyecto Tritryps, además de la tecnología desarrollada para el procesamiento de muestras a gran escala y tamizajes funcionales (high throughput screening), serán herramientas valiosas para 
el diseño de nuevos medicamentos, con efectividad para cada fase de la enfermedad y con los menores efectos secundarios. ${ }^{7,106}$

\section{Genética de poblaciones}

La caracterización de las poblaciones heterogéneas de T. cruzi ha evolucionado desde el estudio de las isoenzimas hasta la determinación de marcadores moleculares (rDNA, microsatélites, miniexones, etc.) específicos para determinar los linajes, los grupos y por último las unidades discretas de tipificación (discrete typing units, DTU) que fueron fundamentales para la identificación de los seis subgrupos: Tc I, Tc IIa-Iie. ${ }^{107-110}$

Se presupone que los patrones epidemiológicos y los diversos perfiles clínicos observados en los individuos con la enfermedad de Chagas se correlacionan sólidamente con la genética de los hospederos y la gran variabilidad encontrada en las poblaciones de parásitos; en realidad, existen estudios que comprueban que ambos factores son determinantes para la evolución de la enfermedad. ${ }^{111} \mathrm{El}$ análisis mediante marcadores genéticos sugiere que la especie T. cruzi es en verdad un complejo de subespecies, correspondientes a los grupos I y II y que tienen variabilidad intraespecífica y coherencia entre la diversidad genética, la patogenicidad y el tropismo. ${ }^{110,112}$ Se ha observado que los parásitos del grupo II (Tc II) tienen relación preferencial con los mamíferos placentarios y, en particular, con las infecciones humanas, por lo que es frecuente en los casos crónicos. Trypanosoma cruzi grupo I de Sudamérica está vinculado con infecciones humanas asintomáticas e infecciones de vectores y reservorios de área selvática en Brasil. ${ }^{113}$ Esta situación es diferente en otras regiones; en los países andinos, por ejemplo, Tc I puede encontrarse en los ciclos domésticos ${ }^{111} \mathrm{y}$ en México las cepas de parásitos detectados en pacientes con cardiopatías y megasíndromes, en los reservorios silvestres y en los vectores, muestran diversidad pero la mayoría pertenecen al linaje TcI. ${ }^{114,115}$ Aun cuando se ha empleado una gran diversidad de marcadores moleculares para determinar la estructura genética de las poblaciones de T. cruzi, todavía no se tiene el panorama completamente definido y no han dejado de aparecer aislados del parásito que no se ajustan a ninguno de los dos grupos o que tienen características de ambos, en términos genéticos y funcionales. ${ }^{116}$ Es necesario contar con un sistema de tipificación que sea confiable para clasificar a las poblaciones de parásitos con la finalidad de optimizar las medidas de control y designar elementos de diagnóstico y pronóstico para las manifestaciones clínicas de la enfermedad de Chagas.

\section{Interacción de Trypanosoma cruzi con sus hospederos}

Se ha propuesto que la patología de la enfermedad de Chagas puede ser efecto de la persistencia del parásito y compuestos derivados de éste dentro del hospedero $^{117-120}$ y de la reacción inmunitaria ocasionada por la infección, pero que de manera descontrolada reacciona contra las células propias del hospedero. ${ }^{121}$ En particular, el perfil clínico de cada individuo es el resultado de un conjunto de interacciones complejas, entre las cuales se encuentran el fondo genético del hospedero, los factores ambientales y sociales y la composición genética del parásito, todo lo cual se complica en las infecciones mixtas y las re-infecciones. ${ }^{122}$ El parásito T. cruzi tiene contacto con varios tipos celulares dentro de los hospederos humanos: células epiteliales, musculares, cardiacas, nerviosas e intestinales; todas ellas, por lo tanto, tienen algún grado de interacción con el parásito. Se ha mostrado que la capacidad de invadir a las células y multiplicarse en ellas es el primer factor que interviene como determinante para el establecimiento de una infección por T. cruzi, dado que no todas las cepas o aislados del parásito se comportan de igual manera con diferentes tipos celulares, tanto in vitro como in vivo. ${ }^{123}$ Todavía no se ha establecido la base molecular que explique este comportamiento. Se ha estudiado el efecto de poseer un particular tipo de complejo principal de compatibilidad (MHC) con la regulación de la respuesta inmunitaria a la infección por T. cruzi y al daño cardiaco. Se ha encontrado que los pacientes que desarrollan miocardiopatías presentan una frecuencia aumentada de HLA-DR16 en comparación con los individuos asintomáticos. Los sujetos con los tipos HLA-DR4 y HLA-B39 parecen ser más susceptibles a la infección por T. cruzi. ${ }^{124}$

En el estudio de las interacciones del parásito con su célula hospedera se ha descrito que la interacción del tripomastigote con los lisosomas de la célula es indispensable para su crecimiento y multiplicación como amastigote. ${ }^{125}$ También cabe mencionar el papel de la transialidasa en la infección de las células, su papel como mediadora de la obtención de moléculas del hospedero por el parásito y sus efectos inmunosupresores, ${ }^{126}$ mientras que al producto del gene lyt1 se le atribuye una función esencial sobre la invasión del parásito y su propiedad hemolítica. ${ }^{127}$ El proceso de invasión se revisó en fecha reciente y está documentado el papel indispensable de las glucoproteínas de la familia de las mucinas en la invasión por los tripomastigotes. ${ }^{128,129}$ El reporte de la secuenciación del genoma de T. cruzi indica que un alto porcentaje de los genes secuenciados pertenece a esta familia. ${ }^{7}$ 
La generación de este conocimiento de interacciones se ha utilizado en particular en el diseño de vacunas contra la infección por T. cruzi o el desarrollo de la enfermedad. Existen pocos estudios que muestren la utilización de moléculas como generadoras de protección en mamíferos; empero, se ha descrito que el tipo de respuesta que podría proteger a los mamíferos de la enfermedad debe ser Th1; $; 130-132$ también se ha señalado que el agotamiento de cualquiera de los dos tipos celulares activos en la reacción inmunitaria incrementa la susceptibilidad del hospedero a la infección. ${ }^{133}$ Se han identificado epítopes que podrían utilizarse en el diseño de péptidos sintéticos como antígenos de inmunización contra el desarrollo del parásito, tales como los epítopes que generan respuestas de linfocitos T CD8+ ${ }^{134} \mathrm{La}$ utilización de vectores de DNA que contienen genes que codifican a proteínas del parásito es efectiva para la protección contra el establecimiento de la infección por T. cruzi; dentro de estos genes se incluyen la proteína de superficie de amastigote 2 y la transialidasa. ${ }^{133,135-137}$

En la búsqueda de alternativas de control de la enfermedad se ha comunicado la utilización de la metodología del ARN interferente para bloquear la expresión de las moléculas de las células de mamífero que actúan como receptores o ligandos para el parásito y con ello evitar la infección de las células. Tal es el caso de dos moléculas constituyentes de la matriz extracelular de las células de mamífero: laminina $\gamma_{1}$ y trombospondina 1 , cuyo bloqueo de expresión evitó la invasión de células humanas en cultivo por el parásito. ${ }^{138-140}$ La disponibilidad de bases de datos genéticos para T. cruzi y los productos de la secuenciación del genoma harán posible la búsqueda de nuevas moléculas que cumplan con las características de generar respuestas inmunitarias protectoras o cambios en el comportamiento de los parásitos dentro de los hospederos humanos, no siempre contra la infección, sino en contra de la devastación de la enfermedad crónica y para evitar la propagación del parásito a otros hospederos humanos, lo cual contribuirá así a controlar la enfermedad de Chagas.

Trypanosoma cruzi pasa por dos etapas de diferenciación y una proliferativa dentro del tracto digestivo del insecto vector. ${ }^{141-142}$ En particular, la última diferenciación da lugar a los tripomastigotes metacíclicos, que constituyen la fase infectante para el hombre y otros mamíferos. In vitro, la transformación de amastigotes en epimastigotes (primera diferenciación) parece ser reversible y estar controlada por la concentración de glucosa. ${ }^{143}$ Esta dependencia puede relacionarse con la presencia de glucosidasas que degradan carbohidratos complejos presentes en la dieta, con la liberación consecuente de carbohidratos simples. ${ }^{144}$ La segunda diferenciación, la metaciclogénesis, ocurre en el recto del insecto y tiene como requisito la adhesión del parásito a este tejido para iniciar el proceso. Se han informado diversos estudios con el objetivo de dilucidar moléculas o receptores de adhesión que intervienen en la metaciclogénesis y conocer cómo el parásito sobrevive dentro del ambiente del tracto digestivo del triatomino. Dentro de ellos, se ha propuesto que las enzimas de digestión no afectan al parásito, ya que existen experimentos que prueban que las catepsinas, enzimas de digestión en Rhodnius prolixus y que se expresan en todos las etapas de desarrollo, ${ }^{145}$ no muestran cambios de expresión entre insectos infectados y no infectados. ${ }^{146,147}$ Existen reportes que hablan de la presencia de moléculas que regulan la dinámica de multiplicación y transformación de T. cruzi dentro del vector, como el factor hemolítico del buche de $R$. prolixus que parece seleccionar a las cepas de $T$. cruzi y que se desarrollan en él; así como los péptidos derivados de la hemoglobina y las lectinas del buche y el intestino. ${ }^{148}$ Los epimastigotes se unen tanto a la superficie del buche como del intestino, pero la diferenciación de los parásitos depende de la adhesión al recto. ${ }^{149}$ Los niveles de expresión del gen de la lisozima dentro del tracto digestivo varían y es menor en el intestino, por lo que podría favorecerse la presencia de parásitos en ese órgano. ${ }^{150}$ La defensina A de R. prolixus existe en altas concentraciones en la hemolinfa (donde no sobreviven bacterias) pero no así en el intestino, donde mataría a los simbiontes de los cuales depende su supervivencia, por lo cual los parásitos no se ven afectados. ${ }^{151}$ Estos reportes sugieren que existen factores dentro del intestino exclusivos de los insectos alimentados que favorecen la multiplicación y diferenciación de los parásitos in vivo. ${ }^{152-154}$ Se ha propuesto que el parásito compite con su vector por los nutrientes y por tanto la frecuencia de alimento condiciona la densidad de la población de parásitos, así como los porcentajes de cada fase de desarrollo en el recto del insecto. ${ }^{155} \mathrm{El}$ mismo grupo de investigación que realizó el trabajo anterior describe que es posible que la diuresis y no los factores de la hemolinfa o los productos de digestión de la hemoglobina induzcan la metaciclogénesis de T. cruzi. ${ }^{156}$ Un elemento común entre los reportes de estos estudios es la discusión acerca de que la metaciclogénesis es altamente compleja y que hace falta mucha más investigación sobre el fenómeno y herramientas más eficaces y precisas para dilucidar todos los factores que participan en el proceso.

\section{Perspectivas para el conocimiento sobre la genética de $T_{\text {. cruzi y los triatominos }}$}

El uso de las herramientas de la genética de T. cruzi puede aplicarse para identificar las moléculas participantes en el reconocimiento, sistemas de señalización y en 
general para conocer las interacciones específicas dentro del vector, todo ello dentro del marco de evidencia que conduzca al diseño de nuevos métodos de control de la enfermedad de Chagas. En este sentido, pueden proponerse algunas líneas de investigación necesarias: a) la utilización de vacunas veterinarias en animales domésticos en contra de componentes esenciales del vector para el desarrollo de los parásitos, de tal manera que al evitar la diferenciación de los parásitos, estos animales domésticos dejen de funcionar como reservorios y riesgo para la transmisión; b) la generación de vacunas humanas contra las proteínas que el parásito presenta dentro del vector, con bloqueo consecuente de la diferenciación de los parásitos dentro del insecto y la interrupción de la transmisión, lo que sería una medida altruista, dado que la persona vacunada no estaría protegida contra la infección, sino que evitaría que otros se infectaran; y c) la generación de triatominos transgénicos, en los cuales se modifiquen por ingeniería genética las moléculas con las que el parásito interactúa como requisito para su desarrollo, de tal modo que los insectos sean resistentes a la infección por T. cruzi.

La expectativa primaria, después de la secuencia de los genomas de los organismos etiológicos y vectores de la enfermedad de Chagas, se basa en contar con un acervo de elementos que permitan no sólo identificar a los individuos infectados sino establecer un pronóstico de la enfermedad de acuerdo con las características genéticas que presente la población del parásito, incidir en el desarrollo de la infección para evitar los daños de la enfermedad crónica y evitar la propagación de la enfermedad por medio de la prevención de la infección en hospederos domésticos. Asimismo, marcadores de genoma permitirán analizar la genética poblacional del vector y su asociación con la modificación, adaptación y conectividad ecológica del hábitat, factores claves para la exposición y el riesgo de transmisión del parásito y, por lo tanto, de la enfermedad. ${ }^{157}$

\section{Agradecimientos}

Este trabajo se realizó gracias a la colaboración de varios grupos de investigación integrantes de la red ECLAT bajo la coordinación del Dr. C.J. Schofield. Este trabajo recibió apoyo económico de las siguientes instituciones: OPS / OMS (proyectos No. OMS A50674 y OMS A30448); CONACYT de México (FOMIX-Morelos: Proyecto No. 2004-CO2-012), "Comisión Sectorial de Investigación Científica" (CSIC) de Uruguay y del Instituto Nacional de Salud Pública de México.

\section{Referencias}

I. World Health Organization. Control of Chagas disease.WHO Technical Report Series 81 I. Ginebra:WHO, 1991.

2.World Bank. World Development Report 1993. Investing in Health. New York: Oxford University Press, 1993.

3. Morel CM, Lazdins J. Chagas disease. Nat Rev Microbiol 2003; I: I4- 15. 4. Dias JC, Silveira AC. Chagas disease in the Americas: current situation and perspectives. Rev Soc Bras Med Trop 2005;38(Suppl 2:5-I3).

5. Schofield C], Jannin J, Salvatella R. The future of Chagas disease Control. Trends Parasitol 2006;22:583-588.

6. Ramsey JM, Tello-López A, Pohls JL. Iniciativa para la vigilancia y control de la enfermedad de Chagas en la República Mexicana. México: Instituto Nacional de Salud Pública, 2003.

7. El-Sayed NM, Myler PJ, Bartholomeu DC, Nilsson D, Aggarwal G, Tran AN, et al. The genome sequence of Trypanosoma cruzi, etiologic agent of Chagas disease. Science 2005;309:409-415.

8. Schofield C], Dias JCP.The Southern Cone Initiative against Chagas disease.Adv Parasitol 1999;42:I-27.

9. Monteiro FA, Escalante AA, Beard CB. Molecular tools and triatomine systematics: a public health perspective. Trends Parasitol 200 I;17:344-347. I0. Mota J, Chacon JC, Gutierrez-Cabrera AE, Sanchez-Cordero V, Wirtz RA, Ordoñez R, et al. Identification of blood meal source and infection with Trypanosoma cruzi of Chagas disease vectors using a multiplex cytochrome b polymerase chain reaction assay.Vector Borne Zoonotic Dis 2007;7(4):617-627.

I I. Lent H,Wygodzinsky P. Revision of the Triatominae (Hemiptera, Reduviidae), and their significance as vectors of Chagas disease. Bull Am Mus Nat His 1979;163: 123-520.

I2. Dujardin J, Panzera P, Schofield CJ. Triatominae as a model of morphological plasticity under ecological pressure. Mem Inst Oswaldo Cruz 1999;94:223-228.

I3. Pereira J, Dujardin JP, Salvatella R, Tibayrenc M. Enzymatic variability and phylogenetic relatedness among Triatoma infestans, T. platensis, $T$. delpontei and T. rubrovaria. Heredity 1996;77:47-54.

14. Panzera F, Hornos S, Pereira J, Cestau R, Canale D, Diotaiuti L, et al. Genetic variability and geographic differentiation among three species of triatomine bugs (Hemiptera-Reduvidae). Am J Trop Med Hyg 1997;57:732-739.

15. Noireau F, Gutierrez T, Zegarra M, Flores R, Breniere SF, Cardozo L, et al. Cryptic speciation in Triatoma sordida (Hemiptera: Reduviidae) from the Bolivian Chaco. Trop Med Int Health 1998;3:364-372.

16. Monteiro FA, Donnelly MJ, Beard CB, Costa J. Nested clade and phylogeographic analyses of the Chagas disease vector Triatoma brasiliensis in Northeast Brazil. Mol Phyl Evol 2004:32:46-56.

17. Marcilla A, Bargues MD, Ramsey JM, Magallon-Gastelum E, SalazarSchettino PM,Abad-Franch F, et al. The ITS-2 of the nuclear rDNA as a molecular marker for populations, species, and phylogenetic relationships in Triatominae (Hemiptera: Reduviidae), vectors of Chagas disease. Mol Phyl Evol 200I;18:136-142.

I8. Panzera F, Ferrandis I, Ramsey J, Ordoñez R, Salazar-Schettino PM, Cabrera M, et al. Chromosomal variation and genome size support existence of cryptic species of Triatoma dimidiata with different epidemiological importance as Chagas Disease vectors. Trop Med Int Health 2006; I I: 1092-I I03.

19. Catala S, Sachetto C, Moreno M, Rosales R, Salazar-Schetrino PM, Gorla D.Antennal phenotype of Triatoma dimidiata populations and its 
relationship with species of phyllosoma and protracta complexes. J Med Entomol 2005;42(5):719-725.

20. Dujardin JP, Schofield CJ, Panzera F. Los vectores de la enfermedad de Chagas. Bruselas: Académie Royale des Sciences d'Outre-Mer, 2002.

21.Abad-Franch F, Monteiro FA. Molecular research and the control of Chagas disease vectors. An Acad Bras Cienc 2005;77(3):437-454. 22. Torrico RA. Hallazgo de Eratyrus mucronatus, infestación natural de "vinchucas" de cerro y Eutriatoma sordida en Cochabamba.Ann Lab Central Cochabamba 1946; 1: 19-23.

23. Dujardin JP,Tibayrenc M,Venegas E, Maldonado L, Desjeux P,Ayala F. Isozyme evidence of lack of speciation between wild an domestic Triatoma infestans (Heteroptera: Reduviidae) in Bolivia.J Med Entomol 1987;24:40-45. 24. Bermudez $\mathrm{H}$,Valderrama F, Torrico F. Identification and characterization of sylvatic foci of Triatoma infestans in Central Bolivia. Am J Trop Med Hyg 1993;49:371.

25. Schofield C]. The biosystematics of Triatominae. In: Service MW, comp. Biosystematics of Haematophagous Insects. Oxford: Clarendon Press, 1988:284-312.

26. Dujardin JP, Schofield CJ, Tibayrenc M. Population structure of Andean Triatoma infestans: allozyme frequencies and their epidemiological relevance. Med Vet Entomol 1998;12:20-29.

27. Panzera F, Dujardin JP, Nicolini P, Caraccio MN, Rose V, Tellez T, et al. Genomic changes of Chagas disease vector, South America. Emerg Infect Dis 2004; 10:438-436.

28. Martinez A, Olmedo RA, Carcavallo RU. Una nueva subespecie argentina de Triatoma infestans. Chagas 1987;4:479-480.

29. Noireau F, Bastrenta B, Catala S, Dujardin JP, Panzera F, Torres M, et al. Silvatic population of Triatoma infestans from the Bolivian Chaco: from field collection to characterization. Mem Inst Oswaldo Cruz 2000;95: I 19-I 22. 30. Schofield CJ, Diotaiuti L, Dujardin JP.The process of domestication in Triatominae. Mem Inst Oswaldo Cruz 1999;94:375-378.

31. Dujardin JP, Bermudez H, Schofield CJ. The use of morphometrics in entomological surveillance of sylvatic foci of Triatoma infestans in Bolivia. Acta Tropica 1997;66: 145-153.

32. Noireau F, Rojas-Cortez MG, Monteiro FA, Jansen AM, Torrico F. Can wild Triatoma infestans foci in Bolivia jeopardize Chagas disease control efforts ? Trends Parasitol 2005;21:7-10.

33. Garcia BA, Zheng LO, Pérez-de Rosas AR, Segura EL. Primer note. Isolation and characterization of polymorphic microsatellite loci in the Chagas' disease vector Triatoma infestans (Hemiptera: Reduviidae). Mol Ecol Notes 2004:4:568-571.

34. Marcet PL, Lehmann T, Groner G, Gurtler RE, Kitron U, Dotson EM. Identification and characterization of microsatellite markers in the Chagas disease vector Triatoma infestans (Heteroptera: Reduviidae). Infec Genet Evol 2006;6:32-37.

35. Picollo MI,Vassena C, Santo-Orihuela P, Barrios S, Zaidemberg M, Zerba E. High resistance to pyrethroid insecticides associated with ineffective field treatments in Triatoma infestans (Hemiptera: Reduviidae) from Northern Argentina.J Med Entomol 2005;42:637-642.

36. Toloza AC, Germano M, Cueto GM, Vassena C, Zerba E, Picollo MI. Differential patterns of insecticide resistance in eggs and first instars of Triatoma infestans (Hemiptera: Reduviidae) from Argentina and Bolivia.J Med Entomol 2008;45:42I-426.

37. Orihuela PL,Vassena CV, Zerba EN, Picollo MI. Relative contribution of monooxygenase and esterase to pirethroid resistance in Triatoma infestans (Hemiptera: Reduviidae) from Argentina and Bolivia.J Med Entomol 2008;45:298-306

38. Zeledón R. Some historical facts and recent issues related to the presence of Rhodnius prolixus (Stal, 1859) (Hemiptera, Reduviidae) in Central America. Entomol Vect 2004; I :233-246.

39. Dujardin JP, Muñoz M, Chavez T, Ponce C, Moreno J, Schofield C). The origin of Rhodnius prolixus in Central America. Med Vet Entomol 1998;12:113-115.
40. Yamagata Y, Nakagawa J. Control of Chagas disease.Adv Parasitol 2006;61:I29-165.

4I.Villegas J, Feliciangeli MD, Dujardin JP.Wing shape divergence between Rhodnius prolixus from Cojedes (Venezuela) and Rhodnius robustus from Mérida (Venezuela). Infec Genet Evol 2002;2:12I-128.

42. Feliciangeli MD, Dujardin JP, Bastrenta B, Mazzarri M,Villegas J, Flores $M$, et al. Is Rhodnius robustus (Hemiptera: Reduviidae) responsible for Chagas disease transmission in Western Venezuela? Trop Med Int Health 2002;7:280-287.

43. Monteiro FA, Barrett TV, Fitzpatrick S, Cordon-Rosales C, Feliciangeli $D$, Beard CB. Molecular phylogeography of the Amazonian Chagas disease vectors Rhodnius prolixus and R. robustus. Mol Ecol 2003; I2:997-1006. 44. Panzera F, Ferrandis I, Ramsey J, Salazar-Schettino PM, Cabrera M, Monroy C, et al. Genome size determination in Chagas Disease transmitting bugs (Hemiptera -Triatominae) by flow cytometry. Am J Trop Med Hyg 2007;76(3):516-52I.

45. Dorn PL, Monroy C, Curtis A. Triatoma dimidiata (Latreille, I8I I): a review of its diversity across its geographic range and the relationship among populations. Infect Genet Evol 2007;7(2):343-352.

46. Zeledón R. El Triatoma dimidiata (Latreille I8I I) y su relación con la enfermedad de Chagas. San José, Costa Rica: INCIENSA/EUNED, I98I. 47. Ponce $C$. Elimination of the vectorial transmission of Chagas disease in Central American countries: Honduras. Mem Inst Oswaldo Cruz 1999;94(Suppl I):417-418.

48. Abad-Franch F, Paucar CA, Carpio CC, Cuba-Cuba CA,AguilarVHM, Miles MA. Biogeography of Triatominae in Ecuador: implications for the design of control strategies. Mem Inst Oswaldo Cruz 2001;96:61 I-620. 49. Harris, K. Taxonomy and Phylogeny of North American Triatominae: Public Health Implications. (Tesis). Atlanta (GA): Moorehouse School of Medicine, 2003.

50. Calderon-Fernandez G, Juarez MP, Ramsey J, Salazar-Schettino PM, Monroy MC, Ordonez R, et al. Cuticular hydrocarbon variability among Triatoma dimidiata (Hemiptera:Reduviidae) populations from Mexico and Guatemala.J Med Entomol 2005;42:780-788.

5I. Lehmann P, Ordonez R, Ojeda-Baranda R, de Lira JM, Hidalgo-Sosa L, Monroy $C$, et al. Morphometric analysis of Triatoma dimidiata populations (Reduviidae:Triatominae) from Mexico and Northern Guatemala. Mem Inst Oswaldo Cruz 2005; 100:477-482.

52. Bargues MD, Klisiowicz DR, Gonzalez-Candelas F, Ramsey JM, Monroy $\mathrm{C}$, Ponce $\mathrm{C}$, et al. Phylogeography and genetic variation of Triatoma dimidiata, the main Chagas disease vector in Central America, and its position within the genus Triatoma. PLoS Negl Trop Dis 2008;2(5):e233. 53. Schofield CJ. Evolución y control del Triatoma dimidiata. En: Taller para el establecimiento de pautas técnicas en el control de Triatoma dimidiata, San Salvador, Documento PAHO OPS/HCP/HCT/2/4/02, 2002:12-18. 54. Schofield C]. Propuestas de estrategias para el control de Triatoma dimidiata en Colombia. En: Primer Taller Internacional sobre Control de la Enfermedad de Chagas (F Guhl, ed.). Bogotá: Universidad de Los Andes, 2005:55-61.

55. Flores A, Magallon-Gastelum E, Bosseno MF, Ordoñez R, Lozano-Kasten $F$, Espinoza B, et al. Isoenzyme variability of five principal triatomine vector species of Chagas disease in Mexico. Infec Genet Evol 200 I; I:2I-28. 56. Martinez F,Alejandre-Aguilar R, Moncada YH, Espinoza B. Molecular taxonomic study of Chagas disease vectors from the phyllosoma, lecticularia, and rubrofasciata complexes. Am J Trop Med Hyg 2005;73:32I-325

57. Breniere SF, Taveira B, Bosseno MF, Ordoñez R, Lozano-Kasten F, Magallón-Gastélum E, et al. Preliminary results of random amplification of polymorphic DNA among triatominae of the phyllosoma complex $(H, R)$. Mem Inst Oswaldo Cruz 2003;98:1033-1038.

58. Martinez FH,Villalobos GC, Cevallos AM, Torre P de L, Laclette JP, Alejandre-Aguilar R, et al. Taxonomic study of the Phyllosoma complex and other triatomine (Insecta: Hemiptera: Reduviidae) species of 
epidemiological importance in the transmission of Chagas disease: using ITS-2 and mtCytB sequences. Mol Phyl Evol 2006;4I(2):279-287. 59. Pfeiler E, Bitler BG, Ramsey JM, Palacios-Cardiel C, Markow TA. Genetic variation, population structure, and phylogenetic relationships of Triatoma rubida and T. recurva (H:R:T) from the Sonoran Desert, insect vectors of the Chagas' disease parasite Trypanosoma cruzi. Mol Phyl Evol 2006;41:209-2II.

60.WHO. Control of Chagas Disease: Second Report of the WHO Expert Committee. World Health Organ Tech Rep Ser 2002;905: I- 109.

61.Abad-Franch F, Monteiro FA,Aguilar VHM, Miles MA. Population-level mitochondrial DNA sequence diversity in Rhodnius ecuadoriensis. Abs. IX European Multicolloquium of Parasitology; 2004; Valencia, Spain.

62. Barbosa SE, Diotaiuti L, Soares RPP, Pereira MH. Differences in saliva composition among three Brazilian populations of Panstrongylus megistus (Hemiptera, Reduviidae).Acta Tropica 1999;72:91-98.

63. Diotaiuti L, Faria Filho OF, Carneiro FC, Dias JC, Pires HH, Schofield C]. Operational aspects of Triatoma brasiliensis control. Cad Saude Publica 2000; 16(Suppl 2):61-67.

64. Ramsey JM, Cruz-Celis A, Salgado L, Espinosa L, Ordonez R, Lopez $R$, et al. Efficacy of pyrethroid insecticides against domestic and peridomestic populations of Triatoma pallidipennis and Triatoma barberi (Reduviidae:Triatominae) vectors of Chagas' disease in Mexico.J Med Entomol 2003;40:912-920.

65. Ramirez C], Jaramillo CA, Delgado MP, Pinto NA, Aguilera G, Guhl

F. Genetic structure of sylvatic, peridomestic and domestic populations of Triatoma dimidiata (Hemiptera: Reduviidae) from an endemic zone of Boyaca, Colombia. Acta Tropica 2005;93:23-29.

66. Ramsey JM,Alvear AL, Ordonez R, Munoz G, Garcia A, Lopez R, et al. Risk factors associated with house infestation by the Chagas disease vector Triatoma pallidipennis in Cuernavaca metropolitan area, Mexico. Med Vet Entomol 2005; 19:219-228.

67. Borges EC, Dujardin JP, Schofield CJ, Romanha AJ, Diotaiuti L. Dynamics between sylvatic, peridomestic and domestic populations of Triatoma brasiliensis (Hemiptera: Reduviidae) in Ceará State, Northeastern Brazil. Acta Tropica 2005;93:1 19-126.

68. OPS-MSF. Curso de capacitación médica en el diagnóstico, manejo y tratamiento de la enfermedad de Chagas. Washington, DC: OPS, 2004. 69. Avila HA, Sigman DS, Cohen LM, Millikan RC, Simpson L. Polymerase chain reaction amplification of Trypanosoma cruzi kinetoplast minicircle DNA isolated from whole blood lysates: Diagnosis of chronic Chagas disease. Mol Biochem Parasitol 1991;48:2 I I-222.

70. Russomando A, Figueredo A, Almiron M, Sakamoto M, Morita K. Polymerase chain reaction-based detection of Trypanosoma cruzi DNA in serum.J Clin Microbiol 1992;30:2864-2868.

7I. Marcon GE,Andrade PD, de Albuquerque DM,Wanderley da S, de Almeida EA, Guariento ME, et al. Use of a nested polymerase chain reaction (N-PCR) to detect Trypanosoma cruzi in blood samples from chronic chagasic patients and patients with doubtful serologies. Diagn Microbiol Infect Dis 2002;43:39-43.

72. Van Voorhis WC, Barrett L, Koelling R, Farr AG. FL-160 proteins of Trypanosoma cruzi are expressed from a multigene family and contain two distinct epitopes that mimic nervous tissues. J Exp Med 1993; I78:68I-694. 73. Lane JE, Olivares-Villagomez D,Vnencak-Jones CL, McCurley TL, Carter CE. Detection of Trypanosoma cruzi with the polymerase chain reaction and in situ hybridization in infected murine cardiac tissue.Am J Trop Med Hyg 1997;56:588-595.

74. Lane JE, Ribeiro-Rodrigues R, Olivares-Villagomez D,Vnencak-Jones CL, McCurley TL, Carter CE. Detection of Trypanosoma cruzi DNA within murine cardiac tissue sections by in situ polymerase chain reaction. Mem Inst Oswaldo Cruz 2003;98:373-376.

75. Avila HA, Pereira JB, Thiemann O, De Paiva E, DeGrave W, Morel CM, et al. Detection of Trypanosoma cruzi in blood specimens of chronic chagasic patients by polymerase chain reaction amplification of kinetoplast minicircle DNA: comparison with serology and xenodiagnosis. J Clin Microbiol 1993;31:2421-2426.

76. Gomes ML, Galvao LM, Macedo AM, Pena SD, Chiari E. Chagas' disease diagnosis: comparative analysis of parasitologic, molecular, and serologic methods. Am J Trop Med Hyg 1999;60:205-210.

77.Vallejo GA, Guhl F, Chiari E, Macedo AM. Species specific detection of Trypanosoma cruzi and Trypanosoma rangeli in vector and mammalian hosts by polymerase chain reaction amplification of kinetoplast minicircle DNA. Acta Tropica 1999;72:203-2I2.

78. Miyamoto CT, Gomes ML, Marangon AV,Araujo SM, Bahia MT, Lana M, et al. Trypanosoma cruzi: sensitivity of the polymerase chain reaction for detecting the parasite in the blood of mice infected with different clonal genotypes. Exp Parasitol 2006; I 12:198-201.

79. Dorn PL, Engelke D, Rodas A, Rosales R, Melgar S, Brahney B, et al. Utility of the polymerase chain reaction in detection of Trypanosoma cruzi in Guatemalan Chagas' disease vectors. Am J Trop Med Hyg 1999;60:740-745.

80. Centurion-Lara A, Barrett L,Van Voorhis WC. Quantitation of parasitemia by competitive polymerase chain reaction amplification of parasite kDNA minicircles during chronic infection with Trypanosoma cruzi.J Infect Dis 1994; I70:1334-1339.

8I. Carvalho MR, Krieger MA,Almeida E, Oelemann W, Shikanai-Yassuda MA, Ferreira AW, et al. Chagas' disease diagnosis: evaluation of several tests in blood bank screening. Transfusion 1993;33:830-834.

82. Umezawa ES, Silveira JF. Serological diagnosis of Chagas disease with purified and defined Trypanosoma cruzi antigens. Mem Inst Oswaldo Cruz 1999;94(Suppl I):285-288.

83. Monteon VM, Guzman-Rojas L, Negrete-Garcia C, Rosales-Encina

JL, Lopez PA. Serodiagnosis of American trypanosomiasis by using nonpathogenic trypanosomatid antigen.J Clin Microbiol I997;35:33|6-3319. 84. Perez-Fuentes R, Sanchez-Guillen MC, Gonzalez-Alvarez C, Monteon VM, Reyes PA, Rosales-Encina JL. Humoral nitric oxide levels and antibody immune response of symptomatic and indeterminate Chagas' disease patients to commercial and autochthonous Trypanosoma cruzi antigen.Am J Trop Med Hyg 1998;58:715-720.

85. Umezawa ES, Luquetti AO, Levitus G, Ponce C, Ponce E, Henriquez

$D$, et al. Serodiagnosis of chronic and acute Chagas' disease with

Trypanosoma cruzi recombinant proteins: results of a collaborative study in six Latin American countries.J Clin Microbiol 2004;42:449-452.

86. Gadelha AA, Vercosa AF, Lorena VM, Nakazawa M, Carvalho AB, Souza $W V$, et al. Chagas' disease diagnosis: comparative analysis of recombinant ELISA with conventional ELISA and the haemagglutination test. Vox Sang 2003;85:165-170.

87. Ramos-Ligonio A, Lopez-Monteon A, Talamas-Rohana P, RosalesEncina JL. Recombinant SSP4 protein from Trypanosoma cruzi amastigotes regulates nitric oxide production by macrophages. Parasite Immunol 2004;26:409-4I8.

88. Chang CD, Cheng KY, jiang LX, Salbilla VA, Haller AS, Yem AW, et al. Evaluation of a prototype Trypanosoma cruzi antibody assay with recombinant antigens on a fully automated chemiluminescence analyzer for blood donor screening. Transfusion 2006;46(I0): I737-I744.

89. Cheng KY, Chang CD, Salbilla VA, Kirchhoff LV, Leiby DA, Schochetman $\mathrm{G}$, et al. Immunoblot assay using recombinant antigens as a supplemental test to confirm the presence of antibodies to Trypanosoma cruzi. Clin Vaccine Immunol 2007;14(4):355-36I.

90. Doménech-Sánchez A,Vila J. Fundamentos, tipos y aplicaciones de los arrays de ADN en la microbiología médica. Enferm Infecc Microbiol Clin 2004:22(I):46-54.

91. Guo Y, Fu Z,Van Eyk JE.A proteomic primer for the clinician. Proc Am Thorac Soc 2007;4(I):9-17.

92. Sartain MJ, Slayden RA, Singh KK, Laal S, Belisle JT. Disease state differentiation and identification of tuberculosis biomarkers via native antigen array profiling. Mol Cell Proteomics 2006;5(II):2102-2II3. 
93. Palacios G, Quan PL, Jabado OJ, Conlan S, Hirschberg DL, Liu Y, et al. Panmicrobial oligonucleotide array for diagnosis of infectious diseases. Emerg Infect Dis 2007; I3(I):73-8I.

94. Rodríguez-Morales AJ. Nuevas perspectivas en el manejo terapéutico de la enfermedad de Chagas. Rev Peru Med Exp Salud Publica 2005;22:123-133.

95. OPS/MSF Regional Consultation Technique on Organization and Structure of the Medical Attention of patient with Chagas disease. Rev Soc Bras Med Trop 2005;38:538-54I.

96. Caffrey CR, Scory S, Steverding D. Cysteine proteinases of trypanosome parasites: novel targets for chemotherapy. Curr Drug Targets 2000; I:155-162.

97. Cazzulo J, Stoka V,Turk V.The major cysteine proteinase of Trypanosoma cruzi: a valid target for chemotherapy of Chagas disease. Curr Pharm Des 200I;7:II43-II56.

98. Urbina JA. Chemotherapy of Chagas' disease: the how and the why.J Mol Med 1999;77:332-338.

99. Urbina JA, Payares G, Sanoja C, Molina J, Lira R, Brener Z, et al. Parasitological cure of acute and chronic experimental Chagas disease using the long-acting experimental triazole TAK-187. Activity against drugresistant Trypanosoma cruzi strains. Int J Antimicrob Agents 2003;21:39-48. 100. Urbina JA, Concepcion JL, Montalvetti A, Rodriguez JB, Docampo R. Mechanism of action of 4-phenoxyphenoxyethyl thiocyanate (WC-9) against Trypanosoma cruzi, the causative agent of Chagas' disease. Antimicrob Agents Chemother 2003;47:2047-2050.

I0I. Tasdemir D, Kaiser M, Brun R, Yardley V, Schmidt TJ, Tosun F, et al. Antitrypanosomal and antileishmanial activities of flavonoids and their analogues: in vitro, in vivo, structure-activity relationship, and quantitative structure-activity relationship studies. Antimicrob Agents Chemother 2006;50: I352-I364.

102. Silber AM, Colli W, Ulrich H,Alves MJ, Pereira CA.Amino acid metabolic routes in Trypanosoma cruzi: possible therapeutic targets against Chagas' disease. Curr Drug Targets Infect Disord 2005;5:53-64. 103. Senkovich O, Bhatia V, Garg N, Chattopadhyay D. Lipophilic antifolate trimetrexate is a potent inhibitor of Trypanosoma cruzi: prospect for chemotherapy of Chagas' disease. Antimicrob Agents Chemother 2005;49:3234-3238.

104. Agusti R, Paris G, Ratier L, Frasch AC, de Lederkremer RM. Lactose derivatives are inhibitors of Trypanosoma cruzi trans-sialidase activity toward conventional substrates in vitro and in vivo. Glycobiology 2004; 14:659-670.

105. Cooper RA, Carucci DJ.Proteomic approaches to studying drug targets and resistance in Plasmodium. Curr Drug Targets Infect Disord 2004;4(I):4I-5I.

106. Sodré CL, Chapeaurouge AD, Kalume DE, de Mendonça-Lima L, Perales J, Fernandes O. Proteomic map of Trypanosoma cruzi CL Brener: the reference strain of the genome project. Arch Microbiol 2009;191(2): 177-84.

107. Brisse S, Dujardin JC,Tibayrenc M. Identification of six Trypanosoma cruzi lineages by sequence-characterised amplified region markers. Mol Biochem Parasitol 2000; I I : 95-105.

108. Barnabe C, Neubauer K, Solari A,Tibayrenc M. Trypanosoma cruzi: presence of the two major phylogenetic lineages and of several lesser discrete typing units (DTUs) in Chile and Paraguay.Acta Trop 2001;78:127-137.

109. Buscaglia CA, Di Noia JM. Trypanosoma cruzi clonal diversity and the epidemiology of Chagas' disease. Microbes and Infection 2003;5:4 I9-427. I I0. Devera R, Fernandes O, Rodrigues-Coura J. Should Trypanosoma cruzi be called "cruzi" complex? A review of the parasite diversity and the potential of selecting population after in vitro culturing and mice infection. Mem Int Oswaldo Cruz 2003;98:1-12.
III. Huete-Perez JA, Flores-Obando RE, Ghedin E, Caffrey CR. Genomic and proteomic approaches for Chagas' disease: critical analysis of diagnostic methods. Expert Rev Mol Diagn 2005;5:52I-530.

I I2. Westenberger SJ, Sturm NR, Campbell DA. Trypanosoma cruzi 5S rRNA arrays define five groups and indicate the geographic origins of an ancestor of the heterozygous hybrids. Int J Parasitol 2006;36:337-346. I I3. Zingales B, Stolf BS, Souto RP, Fernandes O, Briones MR. Epidemiology, biochemistry and evolution of Trypanosoma cruzi lineages based on ribosomal RNA sequences. Mem Inst Oswaldo Cruz 1999;94(Suppl I):159-164.

I I4. Bosseno MF, Barnabe C, Magallon-Gastelum E, Lozano-Kasten F, Ramsey J, Espinoza B, et al. Predominance of Trypanosoma cruzi lineage I in Mexico.J Clin Microbiol 2002;40:627-632.

I I5. Sanchez-Guillen MC, Bernabe C, Tibayrenc M, Zavala-Castro J, Totolhua JL, Méndez-Lopez J, et al. Trypanosoma cruzi strains isolated from human, vector, and animal reservoir in the same endemic region in Mexico and typed as T. cruzi l, discrete typing unit I exhibit considerable biological diversity. Mem Inst Oswaldo Cruz 2006;10I (6):585-590.

I 16. Tibayrenc M. Genetic subdivisions within Trypanosoma cruzi (Discrete Typing Units) and their relevance for molecular epidemiology and experimental evolution. Kinetop Biol Dis 2003;2:12.

I 17. Higuchi MD, Ries MM,Aiello VD, Benvenuti LA, Gutierrez PS, Bellotti $\mathrm{G}$, et al. Association of an increase in CD8+ T cells with the presence of Trypanosoma cruzi antigens in chronic, human, chagasic myocarditis. Am J Trop Med Hyg 1997;56:485-489.

I 18. Higuchi ML. Chagas disease. Importance of the parasite in the pathogenesis of the cardiac chronic disease. Arq Bras Cardiol 1995;64:25I-254

I 19. Jones EM, Colley DG, Tostes S, Lopes ER,Vnencak-Jones C, McCurley TL. Amplification of Trypanosoma cruzi DNA sequences from inflammatory lesions in human chagasic cardiomyopathy.Am J Trop Med Hyg 1993;48:348-357.

120. Jones EM, Colley DG, Tostes SJ. Trypanosoma cruzi DNA sequences in human inflammatory cardiac lesions. Am J Trop Med Hyg 1993;48:348-355. I2I. Correa-Oliveira R, Silva-Gomes JA, Moreira-Lemos E, Cardoso $\mathrm{GM}$, Reis DD,Adad S, et al. The role of the immune response on the development of severe clinical forms of human Chagas disease. Mem Inst Oswaldo Cruz 1999;94(Suppl I):253-255

122. Campbell DA, Westenberger SJ, Sturm NR. The determinants of Chagas disease: connecting parasite and host genetics. Curr Mol Med 2004:4:549-562

123. Neira I, Ferreira A, Yoshida N.Activation of distinct signal transduction pathways in Trypanosoma cruzi isolates with differential capacity to invade host cells. Int J Parasitol 2002;32:405-4I4.

124. Cruz-Robles D, Reyes PA, Monteon-Padilla VM, Ortiz-Muniz AR, Vargas-Alarcon G. MHC class I and class II genes in Mexican patients with Chagas disease. Hum Immunol 2004;65:60-65.

125. Andrade LO,Andrews NW. Lysosomal fusion is essential for the retention of Trypanosoma cruzi inside host cells.J Exp Med 2004;200: I I35- I I 43.

126. Vercelli CA, Hidalgo AM, Hyon SH,Argibay PF. Trypanosoma cruzi trans-sialidase inhibits human lymphocyte proliferation by nonapoptotic mechanisms: implications in pathogenesis and transplant immunology. Transplant Proc 2005;37:4594-4597.

127. Manning-Cela R, Cortes A, Gonzalez-Rey E, Van Voorhis WC, Swindle J, Gonzalez A. LYTI protein is required for efficient in vitro infection by Trypanosoma cruzi. Infect Immun 200 I;69:3916-3923.

128. Yoshida N. Molecular basis of mammalian cell invasion by Trypanosoma cruzi.An Acad Bras Cienc 2006;78:87-III.

I29. Garcia ES, Ratcliffe NA, Whitten MM, Gonzalez MS, Azambuja P. Exploring the role of insect host factors in the dynamics of Trypanosoma cruzi-Rhodnius prolixus interactions. J Insect Physiol 2007;53(I):II-2I. 
130. Kumar S, Tarleton RL. Antigen-specific ThI but not Th2 cells provide protection from lethal Trypanosoma cruzi infection in mice.J Immunol 200I;I66:4596-4603.

I3I. Hoft DF, Eickhoff CS. Type I immunity provides optimal protection against both mucosal and systemic Trypanosoma cruzi challenges. Infect Immun 2002;70:67I5-6725.

132. Schnapp AR, Eickhoff CS, Sizemore D, Curtiss R III, Hoft DF. Cruzipain induces both mucosal and systemic protection against Trypanosoma cruzi in mice. Infect Immun 2002;70:5065-5074.

133.Vasconcelos JR, Hiyane MI, Marinho CR, Claser C, Machado AM, Gazzinelli RT, et al. Protective immunity against Trypanosoma cruzi infection in a highly susceptible mouse strain after vaccination with genes encoding the amastigote surface protein-2 and trans-sialidase. Hum Gene Ther 2004;15:878-886.

134. Martin DL,Weatherly DB, Laucella SA, Cabinian MA, Crim MT, Sullivan S, et al. CD8p T-cell responses to Trypanosoma cruzi are highly focused on strain-variant trans-sialidase epitopes. PLoS Pathog 2006;2:e77. 135. Vasconcelos JR, Boscardin SB, Hiyane MI, Kinoshita SS, Fujimura AE, Rodrigues MM.A DNA-priming protein-boosting regimen significantly improves type I immune response but not protective immunity to Trypanosoma cruzi infection in a highly susceptible mouse strain. Immunol Cell Biol 2003;8I(2): 12I-129.

136. Musalem JS,Vaconcelos JRC, Squanella CC, Ananias RZ, Braga EG, Rodrigues MM.Adjuvant effect of the Propionibacterium acnes and its purified soluble polysaccharide on the immunization with plasmidal DNA containing a Trypanosoma cruzi gene. Microbial Immunol 2006;50:253-263. 137. Garg N, Tarleton RL. Genetic immunization elicits antigen-specific protective immune responses and decreases disease severity in Trypanosoma cruzi infection. Infect Immun 2002;70:5547-5555.

I38. Price HP, Panethymitaki C, Goulding D, Smith DF. Functional analysis of TbARLI, an N-myristoylated Golgi protein essential for viability in bloodstream trypanosomes.J Cell Sci 2005; I 18:83I-84I.

139. Nde PN, Simmons KJ, Kleshchenko YY, Pratap S, Lima MF,Villalta F. Silencing of the laminin gamma-I gene blocks Trypanosoma cruzi infection. Infect Immun 2006;74:1643-1648.

140. Simmons KJ, Nde PN, Kleshchenko YY, Lima MF,Villalta F. Stable RNA interference of host thrombospondin-I blocks Trypanosoma cruzi infection. FEBS Lett 2006;580:2365-2370.

14I. Garcia ES, Guimaraes JA, Prado JL. Purification and characterization of a sulfhydryl-dependent protease from Rhodnius prolixus midgut. Arch Biochem Biophys 1978; 188:315-322.

142. Marquardt WC. Hemimetabolic vectors and some cyclophoran flies and the agents they transmit. In: Beaty BJ y Marquardt WC (ed.). The biology of disease vectors. USA: University Press of Colorado, 1994. 143. Tyler KM, Engman DE. Flagellar elongarion induced by glucose limitation is preadaptive for Trypanosoma cruzi differentiation. Cell Motil Cytoskeleton 2000;46:269-278.
144. Billingsley PF, Downe AER. Ultrastructural localization of Cathepsin $B$ in the midgut of Rhodnius prolixus Stal (Hemiptera:Reduviidae) during blood digestion. Int J Insect Morphol \& Embryol 1988; 17:295-302. 145. Lopez-Ordoñez T, Rodriguez MH, Hernández-Hernández FD. Characterization of a CDNA encoding a cathepsin L-like protein of Rhodnius prolixus. Insect Mol Biol 200 I; 10(5):505-5I I.

146. Ursic-Bedoya RJ, Lowenberger CA. Rhodnius prolixus: identification of immune-related genes up-regulated in response to pathogens and parasites using suppressive subtractive hybridization. Dev Comp Immunol 2007;3I(2):109-120.

147. Garcia ES, Azambuja P. Development and interactions of Trypanosoma cruzi within the insect vector. Parasitol Today 199|;7(9):240-244.

I48. Azambuja P, Garcia ES. Trypanosoma rangeli interactions within the vector Rhodnius prolixus: a mini review. Mem Inst Oswaldo Cruz 2005; 100(5):567-572.

149. Alves CR,Albuquerque-Cunha JM, Mello CB, Garcia ES, Nogueira NF, Bourguingnon SC, et al. Trypanosoma cruzi: attachment to perimicrovillar membrane glycoproteins of Rhodnius prolixus. Exp Parasitol 2007; II6(I):44-52.

150. Azambuja P, Garcia ES, Mello CB, Feder D. Immune responses in Rhodnius prolixus: influence of nutrition and ecdysone.J Insect Physiol 1997;43(6):5।3-519.

|5|. Lopez L, Morales G, Ursic R, Wolff M, Lowenberger C. Isolation and characterization of a novel insect defensin from Rhodnius prolixus, a vector of Chagas disease. Insect Biochem Mol Biol 2003;33(4):439-447.

152. Garcia ES, Gonzalez MS, Azambuja P, Baralle FE, Frainderaich D, Torres HN, et al. Induction of Trypanosoma cruzi metacyclogenesis in the hematofagous insect vector by hemoglobin and peptides carrying alpha-Dglobine sequences. Exp Parasitol 1995;81:255-26I.

153. Garcia ES, Gonzalez MS, Azambuja P. Biological factors involving Trypanosoma cruzi life cycle in the invertebrate vector Rhodnius prolixus. Mem Inst Oswaldo Cruz 1999;94(Suppl I):213-216.

154. Azambuja, P Feder D, Mello CB, Gomes SAO, Garcia ES. Immunity in Rhodnius prolixus: trypanosomatid-vector interactions. Mem Inst Oswaldo Cruz 1999;94(Suppl I):219-222.

155. Kollien AH, Schaub GA. The development of Trypanosoma cruzi in triatominae. Parasitol Today 2000; 16(9):38I-387.

156. Kollien AH, Schaub GA. Trypanosoma cruzi in the rectum of the bug Triatoma infestans: effects of blood ingestion of the vector and artificial diuresis. Parasitol Res 1997;83(8):78I-788.

157. Ibarra-Cerdeña CN, Sánchez Cordero V,Towsend-Peterson A, Ramsey JM. Ecology of North American Triatominae. Acta Trop 2009; I 10(2-3): $178-$ 186. 